\title{
PRETRIAL PUBLICITY AND PROSPECTIVE JURORS: PROBLEMS IN THE USE OF SURVEY RESEARCH
}

\author{
Donald E. Parente and \\ Mario Perez-Reilly \\ (Middle Tennessee State University)
}

\section{Introduction}

Since the U.S. Supreme Court struck down a state conviction on the grounds of prejudicial pretrial publicity (Irvin v. Dowd), ${ }^{1}$ survey research expertise has become a resource for the defense. This has been especially the case in the use of consultants and their survey products in seeking changes of venue and in scientific jury selection (Nietzel and Dillehay, 1982: 41, 1; and 1983: 4, 309). As a result of the increasing acceptance of the use of survey research in legal actions, some scholars and practitioners have expressed concern over its misuse (Goeke, 1984: 1-4; Marner, 1976: 1101-1133; McCormick, 1982: 879-916). Nietzel and Dillehay (1983: 333-334) and others have emphasized the problems and prospects associated with the use of opinion surveys in support of motions to change venue. ${ }^{2}$

This study examines two additional problems, not addressed by others, that are likely to be encountered when social science expertise is utilized in petitioning a change of venue. First is the danger of reading too much into questionnaire responses, and second is culling information in order to make a case.

\section{The Factual Context}

This study also examines the impact of pretrial publicity by the news media (i.e., newspapers and television) on the predisposition of potential jurors in an upcoming criminal trial. The validity of the claims made by the defense counsel in a motion for a change of venue and the dangers in using survey research data in its pursuit are also scrutinized. The motion for a change of venue concerned an accused person who had been indicted for first degree murder after the stabbing death of his ex-wife during an altercation in the county hospital in 1983. The court-appointed counsel sought a change of venue based upon the notion of prejudicial Pretrial publicity. In Tennessee a court may consider granting a change of venue if:

The degree to which the publicity complained of has permeated the arena from which the venire is drawn...and other factors dealing with jury selection. ${ }^{4}$ 
Thus, the defense "...need only show that a fair trial could not be had," in order to secure a change of venue.

The counsel for the defense engaged a public relations consultant to assemble and analyze information obtained through survey research to be presented in court in support of a claim of prejudicial pretrial publicity. Such information, it was assumed by defense counsel, could establish that under an existing climate of prejudicial pretrial publicity. Such information, it was assumed by defense counsel, could establish that under an existing climate of prejudicial pretrial publicity, a fair trial probably could not be had. The defense sought to demonstrate that because of pretrial publicity, potential jurors had been prejudiced against the defendant. The defendant's motion alleged that there was:

(1) extensive media coverage of a prejudicial and inflamatory nature by newspapers, television newscasts, and radio stations,

(2) a high level of awareness about the crime and subsequent pretrial incidents,

(3) and an ensuing predisposition...to believe that the accused was guilty by the community at large, including potential jurors. ${ }^{6}$

\section{Survey Design and Data Sources}

The authors of this study had access to all the data generated by questionnaire interviews of potential jurors. One of the authors participated in the training of interviewers and supervision of the interviews (conducted by telephone) as well as the coding, verification, and key-punching of the data. Other persons (but none of the authors of this study) employed by the retained public relations consultant performed the analysis presented in court by the consultant in a brief supporting the petition for a change of venue.

The questionnaire, which contained thirty-two information items, was administered to a random sample of 592 households. Only respondents who indicated that they were registered to vote in one of the two counties comprising the judicial district having jurisdiction in the murder case were interviewed for the full length of the questionnaire. Interviewees who indicated that they were not registered voters were not questioned further. About ninety (90) of the persons contacted refused to participate. A sample of 144 registered voters completed the interview.

Counsel's interest centered on the information yielded by questions about a respondent's age, sex, length of residence in the county, newspapers read, television most often watched for local news, and weekly exposure to televised newscasts. Four informational probes, designed to determine a respondent's 
knowledge of the criminal case, were crucial to the defense's petition for a venue change. Questions concerning the respondent's extent of familiarity with the case and predisposition to judge the accused guilty or innocent were also asked. What follows is a partial report of the results of the study.

\section{Hypotheses and Data Analysis}

Before any formulation of hypotheses and the concomitant data analysis, a description of the structure of informational opportunities is in order. The various patterns of interaction between potential jurors and media are summarized in tables 1,2 , and 3 . Table 1 highlights the distribution of potential newspaper sources of information (as reported by respondents). Table 2 summarizes the pattern of potential juror's preference for a particular television channel as a local newscast source. Table 3 outlines the pattern of weekly attention to telecasts of local news. These tables suggest the existence of an informational environment replete with opportunities for a prospective juror to seek information if he or she so desires. Prospective jurors may be characterized as: readers of one or more newspapers, viewers of one or more television news channels, and consumers of televised local news almost on a daily basis. In such a setting, presumably there are ample opportunities for pretrial publicity to reach the potential juror. The following analysis examines the consequences of the pattern of information exchange.

\section{Table 1}

The Daily Press as a Source of News : Readership and Subscriptions*

\begin{tabular}{lrrr}
\hline Newspaper & Respondents Who Read & Percent \\
Nashville Banner & 22 & $(18)^{*}$ & $15(12)$ \\
The Tennessean & 55 & $(32)$ & $38(22)$ \\
News Journal & 83 & $(66)$ & $58(45)$ \\
Morning Press & 32 & $(25)$ & $22(17)$ \\
Courier & 16 & $(12)$ & $11(8)$ \\
Other & 10 & $(6)$ & $7(4)$ \\
None & 16 & $(12)$ & $11(8)$
\end{tabular}
read at least every other day?

Percentages and frequencies are not additive due to multiple readerships and subscriptions.

*Figures in parenthese refer to subscriptions. 


\section{Table 2}

Television Channel

Most Watched for Local News

\section{Channel}

WNGE-2

WSMV-4

WTVF-5

Other

None

\section{Respondents Who Watch}

31

64

57

4

7

\section{Percent}

22

44

40

3

5

Source Question: What TV station do you watch most for local news?

\section{Table 3}

Frequency of Attention to Local TV News

How Often Watched Number Saying

Percent

Almost every night

2 to 3 days weekly

101

Once a week

29

70

Hardly ever

Never

No answer

5

20

5

4

3

2

4

2

1

3

Source Question: How often would you say that you watch TV news?

Court records support the defense's claim that all the news media within the jurisdiction gave extensive and repeated coverage of the murder case. In a few instances, prejudicial comments appeared in media editorials. However, most of the coverage was objective.

In order to examine the validity of the defense's claims about the impact of pretrial publicity, the following propositions are tested:

1. Exposure to newspapers and television tends to enhance awareness of the case.

2. Awareness of the case tends to lead to a perception of the accused as guilty. 
Securing a change of venue in a criminal case is a very difficult enterprise. In order to validate a claim of prejudicial publicity, counsel must establish convincingly that (a) levels of awareness about the case are inordinately high; that (b) there is a preponderant predisposition to find the defendant guilty; that, (c) because of a predisposition to presume guilt, an impartial jury cannot be impaneled; and (d) that if the evidence is convincing up to this point, the conclusion may be drawn that a fair trial cannot be had. The testing of the two propositions addresses these substantive obstacles.

Table 4 examines the effect that media exposure has on case awareness. For the sake of economy only one table is presented here. In this table the information probe that yielded the largest proportion of respondents saying that they can recall the case is summarized.

\section{Table 4}

Media Exposure and Awareness of the Case

\begin{tabular}{lcrcc}
\hline Perception of & \multicolumn{5}{c}{ Type of Media Exposure } \\
the Case: & TV and & TV & Newspapers & \\
& Newspapers & Only & Only & None \\
Aware & 34 & 29 & 56 & 50 \\
Unaware & 66 & 71 & 44 & 50 \\
Percent & 100 & 100 & 100 & 100 \\
$n$ & $(118)$ & $(14)$ & $(9)$ & $(2)$
\end{tabular}

Chi-square: 2.19

$\mathrm{p}:>.05$

$d f .=3$

Source Question: Do you know or have you heard or seen anything about a case involving an accused person by the name of..........?

The results illustrated in Table 4 negate the proposition that media exposure tends to lead to awareness of the case. The results are not significantly different than can be expected by chance. Only in the case of respondents who are limited to reading newspapers is there a greater proportion indicating being aware of the case, but this proportion is not significantly greater than is to be expected by chance. The proportion of the total sample that is aware of the case amounts to only 35 percent (50/143). Therefore, a claim of the existence of inordinately high levels of awareness is not supported by these figures. Consequently, proposition 1 is rejected.

According to Table 5, proposition 2 is also rejected. 
Table 5

Awareness of the Case and

Presumption of Guilt

$(n=141)$

PERCEPTION OF

Perception of CAse

DEFENDANT: Aware Unaware

\begin{tabular}{|c|c|c|}
\hline Guilty/not Guilty & 39 & 26 \\
\hline No Opinion & 61 & 7. \\
\hline Percent & 100 & 100 \\
\hline$n$ & 44 & 97 \\
\hline Chi-squ & $\begin{array}{r}2.395 \\
\quad .05 \\
=\quad 1\end{array}$ & \\
\hline
\end{tabular}

Source Question: Based on what you know about this case, would you say that (the defendant) is: Guilty? Not Guilty?

As in the case for Table 4, only the probe that yielded the greatest number of respondents indicating that they can recall the case is cross-tabulated against the disposition to pass judgment on the accused. Respondents who indicate that the accused is guilty and those who say that he is not guilty are combined into one category (only two persons find the department not guilty). Two respondents are left out of the analysis because they refused to answer the question about the guilt or innocence of the accused. In this cross-tabulation it can be seen that only 39 percent of those respondents who indicate awareness of the case have formed an opinion about the guilt or innocence of the accused and this proportion is not significantly higher than the proportion of those who have formed an opinion among unaware respondents ( 29 percent). Also, it is evident that the aware respondents who have formed an opinion comprise only about 12 percent of the total sample (17/141). The overall sample is predisposed to have no opinion about the question of guilt or innocence. It is this group of respondents that most likely become jurors in a case. In conclusion, a case cannot be made that because of media coverage there is an ensuing predisposition to believe the accused guilty.

\section{Dangers in the Use of Survey Research}

Among the potential dangers in the use of survey research in the courtroom, two, in particular, are worthy of attention: 
(1) reading too much into the responses to a question, and

(2) culling information for the purpose of making a case.

The attempt to make a case for a change of venue (by the defense) was based on the interviewees' responses to the question: "What do you know, or have you heard about this case or trial?" (This question was asked after three other questions had been asked in order to determine if the respondent is aware of the case.) An answer to this question may have one of two meanings: "What I know (or have heard) about this case I knew before this interview and here is what I know," or "What I know about this case is inferred from the questions I was asked and here it is." Counsel and the expert witness are assuming incorrectly that a positive answer to this question (volunteering details about the case) suffices to isolate knowledgeable respondents. A tabulation of the answers to this question would seem to demonstrate that a significantly larger portion of the sample had knowledge of the case (See Table 6a.).

\section{Table 6a}

Reported Knowledge of the Case (or Trial)

\begin{tabular}{lcc}
\hline Respondents & $n$ & Percent \\
Have knowledge & 101 & 70 \\
Have no knowledge & 43 & 30 \\
Total & $144 *$ & 100 \\
*There is a variable of 1 between this table and Table 4.
\end{tabular}

The claim of prejudicial publicity is based on a cross-tabulation of this information against information about the respondents' position on the guilt or innocence of the accused. The supporting affidavit reads:

...of the 70 percent who stated they had heard about the case, 58 percent stated they had formed an opinion about the case; and that of the 58 percent, 95 percent said they believed the defendant guilty...(Affidavit in Support...:1-2)

This handling of percentages is misleading; it conceals more than it reveals. Table $6 \mathrm{~b}$ illustrates what happens when knowledge of the case is cross-tabulated against predisposition toward the accused. What the table demonstrates is that, 
in spite of the expert-counsel claim, 100 respondents (approximately 69 percent, including 57 respondents who comprise 56 percent of those respondents who report that they have knowledge of the case) in the total sample have not arrived at an opinion about the guilt or innocence of the accused. This table suggests that there is a substantial majority of prospective jurors who are either unaffected by the information they report having about the case; or who actually know nothing about the case other than what they have heard (or learned) through the questionnaire. This interpretation of the data is not taken into consideration in the claim for venue change. The information that was culled in the presentation to the court is enclosed in a broken rectangle.

\section{Table 6b}

Respondent's Reported Knowledge of the Case

(Part A)

Related to Attitude Toward the Defendant

Defendant is: Has Knowledge No Knowledge

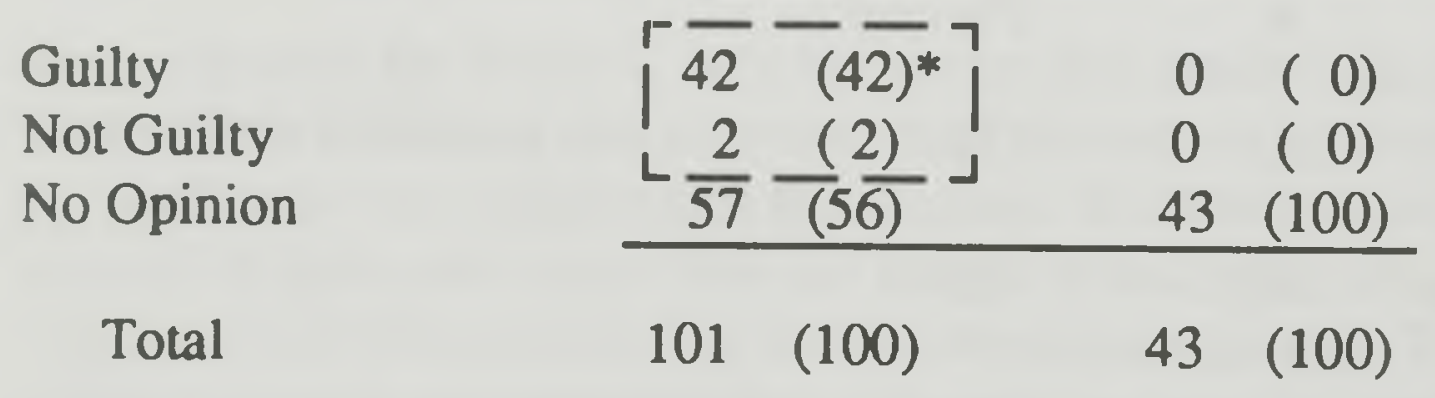

(Part B)

As a Percent of the Total Sample

Defendant is:

$n$

Guilty

Not Guilty

$42(29)^{*}$

No Opinion

Total144@(100)

*Percentages are in parentheses

@Table 4, n=143 
The answers to the question purporting to measure whether respondents did or did not know about the case might have been induced by question learning on the part of those unaware respondents who prior to answering that question had responded to three previous questions (questions that contained minimal information about the case) that they could not recall the case. Content analysis (by one of the persons involved in the administration of the questionnaire) of the information supplied by respondents about the case reveals three different groups of respondents: one group of 46 ( 32 percent) report truthful details about the case in excess of the minimal information contained in the questions designed to give the respondents minimal assistance in recalling the case; a second group, 55 (38 percent of the total sample), whose reports contain partially correct information (only that which coincides with the information contained in the questions designed to assist recall); and a third group, 43, who have no recollection of the case (30 percent). In any analysis and interpretation of questions such as these, care needs to be exercised that too much is not read into the answers to the questions. Respondents, it would be reasonable to expect, can learn from a questionnaire.

\section{Conclusions}

In this study, the presumed media influences upon the awareness of a murder case by potential jurors have been examined. Analysis of survey research data has revealed that in the case in question, media influences upon prospective jurors' awareness of the case and their predispositions toward the defendant were not significant. The claim of prejudicial pretrial publicity pursued by the defendant's counsel has been found not to be supported by the analysis of the pattern of potential juror's responses generated by survey research. Potential jurors, it has been found, had not succumbed, in any significant proportions, to the tendency to prejudge the defendant.

Two difficulties related to the reliance on survey research to support venue changes have been discerned and explained; reading too much into questionnaire responses and culling information to make a case. In view of these difficulties, it is suggested that care be exercised in ascertaining the reliability of responses to survey questions designed to measure familiarity with a case and substantive knowledge about the case. A forthcoming study by these authors reports on the use of the placebo effect in a field quasi-experiment to examine questionnaireinduced learning, as it is suspected to be in evidence in case-related survey research. 


\section{Endnotes}

1336 U.S. 717 (1961).

${ }^{2}$ Judicial conservatism, inherent weakness in survey methodology, weakness in sampling and survey item construction, and the criterion problem.

${ }^{3}$ The case was State of Tennessee v. Harold Lawson, Rutherford City. C. Ct. (1983). Venue change was denied and the defendant was convicted of second degree homicide. The case is currently on appeal before the State Supreme Court.

"the court held in Tennessee v. Hoover: 594 SW ed.,Tenn. Ct. App. (1979). Cited in "Brief in Support of Defendant's Motion for a Change of Venue," Rutherford Cty. C. Ct. (9-5-83).

${ }^{5}$ According to Rule 21(a), Tenn. Rules of Ct. Proc.

6"Brief in Support...": 2-3.

\section{References}

Gocke, Joseph R. (1984). "Survey Research in Legal Actions," in A Total View:The Newsletter of Marketing Research Methods. Princeton: Total Research Corporation.

Marner, Ronald L. (1976). "Opinion Polls and the Law of Evidence," Virginia Law Review. 62: 1101-1133.

McCormick, M. (1982). "Scientific Evidence: Designing a New Approach to Admissibility," Iowa Law Review. 67: 879-916.

Nietzel, Michael T., and Dillehay, R.C. (1982). "The Effects of Variations in Voir Dire Procedures in Capital Murder Trials," Law and Human Behavior. 6:1-13.

(1983). "Psychologists as Consultants for Changes of Venue," Law and Human Behavior. 7: 309-335. 